DOI - https://doi.org/10.5965/2316796309172020015

\title{
Fatores Humanos no design de serviços: Perfil de consumo do público idoso em supermercados
}

\section{Human factors in service design: Consumption profile of the elderly population in supermarkets}

Marcelo Pereira Demilis ${ }^{1}$

Alexandre Amorim dos Reis ${ }^{2}$

Giselle Schmidt Alves Diaz Merino ${ }^{3}$ 


\section{Resumo}

O estudo da experiência do usuário ainda é algo recente, com definições diversas, o que dificulta a delimitação dos fatores que compreendem a experiência de consumo. Em contraponto, têm-se também as diferenças culturais, sociais e de perfil que influem e resultam em diferentes experiências de compras e, finalmente, diferentes respostas do consumidor. Um exemplo disso é a utilização de serviços de supermercados por usuárioidosos. Porisso, objetivou-se identificar as características de perfil do público idoso usuário de um supermercado na grande Florianópolis, com intuito de estudar experiência desse público utilizando esse tipo de serviço. Neste artigo é apresentado os resultados obtidos das entrevistas semiestruturadas realizadas com 150 usuários idosos do supermercado de estudo com relação ao uso desse serviço, e fazer um paralelo com características gerais dos idosos brasileiros. Por meio da coleta realizada pode-se determinar, evidenciar e delimitar algumas características do perfil de consumoeusodoserviçode supermercado por esse públ particularidades de comportamento. Determinou-se a faixa etária que mais utiliza o serviço, suas preferências,
frequência e motivações de utilização do supermercado, meios de transportes utilizados, diferenças no perfil masculino e feminino. E por fim fez-se a correlação dos resultados com características cognitivas e motoras particulares desse público.

Palavras-chave: Design de Serviços, factors. Experience of use (Consumption). Fatores humanos. Experiência de uso Old man. Supermarket. (Consumo). Idoso. Supermercado.

${ }^{1}$ Mestre em Design, UDESC (celodemilis@gmail.com)

2 Doutor em Engenharia, UFSC (alexandre.a.reis@gmail.com)

3 Doutora em Engenharia, UFSC (gisellemerino@gmail.com)
ISSN: $2316-7963$

\section{Considerações Iniciais}

O número de idosos no Brasil e mundo cresce a cada ano. Dados do IBGE (2017) estimam que o percentual de brasileiros com mais de 60 anos de idade, até o ano 2030 representará $18,62 \%$ da população. Assim, o Brasil está se tornando um país da terceira idade e precisa voltar suas atenções para as necessidades dos senescentes (SANTOS et. al., 2009). O envelhecimento é um processo natural, no qual há um decréscimo progressivo de aspectos físicos e cognitivos. Os idosos começam a mostrar outro estilo de vida, saem para lazer, viajam, vão aos teatros, bailes, bingos, clubes, universidades abertas à terceira idade, ao invés de ficarem em casa, isolados. Porém, atualmente existe a enorme defasagem de produtos e serviços especializados que atendem efetivamente o consumidor idoso (BALLSTAEDT, 2007).

A potencialidade desse público de consumidores no Brasil, devido ao aumento da expectativa de vida e ascensão econômica, revela a necessidade do desenvolvimento de uma maior atenção voltada para esta parcela da população. Empresas que fornecem serviços, e que acabam sendo usados também por pessoas de terceira idade, muitas vezes não levam em consideração reais necessidades, vontades e condições desses indivíduos. Um exemplo dessa realidade são os supermercados. Conforme Petermans e Van Cleempoel (2010), pesquisas sobre experiências de compra dos consumidores idosos em supermercados são relativamente raras. A maior parte delas é oriunda da América do Norte e se concentra em experiências de compras, comportamento do patronato, bem como a identificação de atributos que idosos valorizam.

Com base nessas percepções, objetivou-se, dentro do escopo da ergonomia organizacional, objetivou-se identificar as características de perfil do público idoso usuário de um supermercado na grande Florianópolis, com intuito de estudar experiência desse público utilizando esse tipo de serviço. Quanto à forma de abordagem, este artigo caráter quantitativo e qualitativo, pois realiza a coleta de dados por meio de entrevistas estruturadas, semiestruturadas e observação. Segue posteriormente com a análise qualitativa a partir da interpretação dos dados coletados, dando-lhes significados e características. Categoriza como descritivo-exploratório por tanger o aprofundamento e familiaridade com o tema, e visar a descrição das características do fenômeno (GIL, 2007).

A seguir serão apresentados os resultados obtidos das entrevistas realizadas com 150 usuários idosos de um supermercado da região da Grande Florianópolis com relação ao uso desse serviço, e os paralelos realizados com base nas características gerais dos idosos brasileiros. Assim, pode-se determinar, evidenciar e delimitar algumas características do perfil de consumo e uso desse tipo de serviço por esse público.

\section{Fundamentação Teórica: $O$ consumidor idoso e o supermercado}

A satisfação de consumo dos idosos não provém apenas do ato de consumir para a obtenção de bens tangíveis, mas de consumir, enquanto procuram experiências intangíveis, como se sentir bem-vindos em um supermercado, por exemplo, ter uma conversa amigável ou apreciar o ambiente, apreciar um bom serviço (KIM; KANG; KIM, 2005; SHERMAN; SCHIFFMAN; MATHUR, 2001). Burt e Gabbott (1995) mostram que os compradores idosos também podem se envolver em compras como forma de socializar com os seus amigos.Portanto, Petermans e Van Cleempoel (2010) apontam que as lojas de varejo, quando devidamente concebidas para satisfazer as necessidades e desejos 
do mercado dos idosos, podem aumentar fortemente experiências de compras desses consumidores.

Um supermercado pode se diferenciar pela forma que presta os serviços, o uso de diferentes tecnologias, olhares particulares para o público que atende, propondo por exemplo, serviços voltados para idosos. Supermercados direcionados ao idoso surgiram em países e regiões desenvolvidos como Alemanha, Reino Unido, EUA para atender às necessidades e vontades desse público (PETERMANS; VAN CLEEMPOEL, 2010), países em desenvolvimento, como o caso do Brasil, já possuem consumidores potenciais, destacando-se como um mercado em ascensão. Esses estabelecimentos europeus foram desenvolvidos a partir de estudos em torno do comportamento desses indivíduos, ponderando-se aspectos cognitivos, físicos, fisiológicos e sociais, com intuito de melhor entendimento do idoso. No entanto, as diferenças culturais resultam em diferentes experiências de compras e, finalmente, diferentes respostas do consumidor dentro do mercado para idosos (BURT; GABBOTT, 1995). Por isso é preciso entender a realidade do consumidor idoso brasileiro em supermercados para poder perceber suas necessidades e vontades pontuais com intuito de proporcionar a melhor experiência para esse público.

Contudo, com base em levantamentos bibliográficos e pesquisa de campo, são perceptíveis algumas necessidades e vontades pertinentes aos idosos de outras localidades do globo e que são similares às necessidades e vontades do idoso brasileiro. As pessoas com mais de 60 anos querem geralmente desfrutar a vida enquanto pode, ficar ativo, continuar a consumir, e começar a vivenciar experiências com novas tecnologias (Balazs, 1994). Isso também é verdade para a geração dos "babyboomers" (pessoas nascidas entre os anos de 1946 e 1964) (GREER HUSS PACE, 2006). Babyboomers e as pessoas com mais de 60 anos apresentam uma maior tendência para se aposentar mais cedo e, assim ter mais tempo para o lazer, utilizando-o para compras e gastos (PETERMANS; VAN CLEEMPOEL, 2010). Eles preferem fazer compras em um ambiente de varejo agradável (SCHMIDT et. al., 1994).

Outros aspectos também foram percebidos tanto em artigos levantados em revisões bibliográficas sistemáticas (Demilis, 2017), quanto em pesquisa de campo em supermercados, conversas informais com idosos e observação do uso do serviço:

Idosos valorizam os aspectos práticos da qualidade do produto e facilidade de navegação no ambiente do supermercado. Dão valor para a melhoria da experiência de compra, variedade e proximidade a outros serviços. Isto é, valorizam quando o estabelecimento oferece serviços complementares como farmácia, caixa eletrônico, etc. E devido à boa experiência vivida, gostam de frequentar o mesmo local, demonstrando certa resistência a mudanças (grau de fidelização) e apreciação pelo que já conhecem.

Não fazem questão de pegar filas especiais; alguns desses por não se sentirem da mesma maneira em que são retratados no pictograma atual do idoso (figura de uma pessoa curvada, usando bengalas, frágil). Por outro lado, não apreciam pegar filas demoradas e até preferem frequentar horários mais condizentes com a sua rotina e com menos fluxo de pessoas.

Não se preocupam tanto com os preços diante da praticidade, familiarização e qualidade do serviço. Contudo, alguns mesmo assim, acabam por ir a estabelecimentos diferentes para compra de produtos de hortifruti, por exemplo, pela variação na

qualidade, variedade e preços.

Veem o supermercado como uma forma de socializar (com colaboradores, conhecidos ou amigos).

É visível que não apenas aspectos físicos, mas também aspectos sociais são valorizados e, portanto, podem ser considerados a chave para melhorar a experiência de compra dos consumidores idosos. Petermans e Van Cleempoel (2010) apontam para concepção de lojas de varejo que satisfaçam as necessidades e desejos desse público e que ofereçam uma boa experiência de compra, é necessário dar atenção a dois aspectos:

A importância dos aspectos físicos e espaciais do ambiente de supermercados;

A ênfase que os idosos dão aos aspectos sociais da loja de varejo.

Aspectos sociais mostram-se tão importantes quanto os físicos e dizem respeitos às relações sociais. Estas, por sua vez, podem ter um papel essencial para manter ou mesmo promover a saúde física e mental (HOUSE, 1981; COCKERHAM, 1991). Pesquisas demonstram que as relações sociais são capazes de moderar o estresse em pessoas que experienciam problemas de saúde, a morte do cônjuge ou mesmo crises financeiras (SILVERSTEIN e BENGSTON, 1994). Os efeitos positivos do suporte social estão associados com a utilidade de diferentes tipos de suporte fornecidos pela família (emocional ou funcional). Especificamente sob a presença de suportes sociais é esperado que pessoas idosas se sintam amadas, seguras para lidar com problemas de saúde e tenham elevada autoestima (CICIRELLI, 1990). Ramos (2001) afirma que as deficiências em habilidades sociais parecem constituir um fator de vulnerabilidade para a baixa qualidade de vida e para a depressão em indivíduos da terceira idade. A deterioração da saúde pode ser causada não somente por um "processo natural", mas também por falta ou baixa qualidade de relações sociais e vice-versa. Nessa perspectiva, supermercados são oportunidades que esses indivíduos possuem de ter um maior envolvimento social (CARÙ; COVA, 2003; DOUGLAS; ISHERWOOD, 2006; DEMILIS, 2015).

Outro ponto importante a ser observado diz respeito à faixa etária do idoso. Para designar quem é idoso, não se deve usar apenas a idade cronológica como parâmetro, pois essa apenas mede o tempo, os anos que passaram, e assim esse aspecto cronológico do envelhecimento tem apenas um sentido legal e social (DEBERT, 1999). Por essa razão, adotou-se na pesquisa, para efeito comparativo e análises mais condizentes dois modelos de faixas etárias: um adotado pelo IBGE e outro adotado pela Organização Mundial de Saúde (OMS ou WHO). Enquanto o IBGE subdivide os idosos em nove faixas, a OMS classifica envelhecimento em quatro estágios:

\begin{tabular}{|l|l|}
\hline \multicolumn{2}{|c|}{ Tabela T- Faixa etária OMS } \\
\hline CLASSIFICAÇÃo & FAIXA ETÁRIA \\
\hline Meia - idade & 45 a 59 anos \\
\hline Idoso & 60 a 74 anos \\
\hline Velho & 75 a 89 anos \\
\hline Muito velho & Acima de 90 anos \\
\hline \multicolumn{2}{|c|}{ Fonte: OMS (1996) }
\end{tabular}

HFD, v.9, n 17, p. 14-33, junho 2020 
Logo,entenderquemsãoosconsumidores idososdoestabelecimento, comportamentos e suas características funcionais, sociais e emocionais particulares e seus gostos, pode ajudar os varejistas no desenvolvimento de uma estratégia de marca própria para o supermercado. Além disso, pode ajudar os designers a criar lojas de varejo de tal forma que os compradores idosos estejam à vontade com os seus arredores e queiram utilizar o serviço novamente. Aplicando a estratégia de marca, bem como fatores relacionados à ergonomia organizacional, o entendimento das necessidades do usuário idoso e sua forma de consumo, para a prática do design da maneira correta, poderá ajudar a loja a criar um ambiente de varejo melhor sucedido (BRIGHAM, 2005). Portanto, o varejista deve se esforçar para criar valor através da construção de relações, intuitivas pessoais com os consumidores, a fim de fazê-los se sentir aliados com a marca ou loja (PINE E GILMORE, 1999, 2008) e terem uma melhor experiência de uso do serviço.

\section{Procedimentos Metodológicos}

O procedimentos metodológicos consistiram na coleta de dados mediante uma entrevista estruturada direta, abordando-se o usuário idoso (pessoa com 60 anos ou mais) em um supermercado da grande Florianópolis, e aplicando-se um questionário semiestruturado, por meio de entrevistas. Em um segundo foi realizada a análise dos resultados das primeira etapa, avaliando os dados coletados, e determinando, por meio de estatística descritiva, padrões de comportamento do usuário idoso entrevistado.

\subsection{Supermercado}

Para a realização da coleta de dados, utilizou-se um supermercado da região metropolitana de Florianópolis, Santa Catarina. O projeto de pesquisa foi submetido e aprovado no Conselho de Ética (CEP) local conforme Resolução $n^{\circ} 466 / 2012$ - CNS, parecer no. 018946/2015, CAAE 42937214.2.0000.0118. Assim os usuários idosos deste supermercado foram tratados como modelo para representar a população idosa da cidade. O estabelecimento possuía $4100 \mathrm{~m}^{2}$ de área de venda e $10000 \mathrm{~m}^{2}$ de área total, funciona desde abril de 2012 , oferecendo a venda no varejo ao consumidor final, atendendo, para a data da pesquisa, um público de 4300 (média diária). Não possuía estratégia específica para 0 atendimento ao idoso, porém oferecia atendimento preferencial nos caixas, vagas de estacionamento exclusivas e carrinhos motorizados elétricos para usuários com dificuldades de locomoção.

\subsection{Análise de dados}

Os dados foram tabulados e divididos em: informações de cadastro, dados referentes ao uso do supermercado (frequência de ida, transporte utilizado, motivação de uso, preferências) e questões abertas referentes a opiniões e observações. Os dados referentes às informações de cadastro e informações sobre o uso do supermercado foram contabilizados, agrupados e quantificados gerando gráficos e tabelas para cada informação obtida (sexo, média de idade, faixas etárias, frequência de utilização do serviço, transporte utilizado, motivação de uso do serviço, apreço pela conversa) e, posteriormente, criar correlações e cruzamentos entre as informações.

Para tratamento dos dados foi apresentada a estatística descritiva dos sujeitos do estudo. Foram analisadas as informações referentes ao: cadastro dos indivíduos da coleta e uso do supermercado. A partir da contabilização dessas informações, foram verificados os dados que tinham relações ou que pudessem ser cruzados, gerando tabelas e gráficos de dupla entrada. As médias de idade foram calculadas e comparadas com as médias de idade da população idosa brasileira. Faixas etárias das amostras foram separaras e comparadas com a faixa etária da população idosa de Florianópolis.

Os quantitativos da amostra e da população idosa de Florianópolis foram separados de acordo com a faixa etária usada e comparados entre si. Dados relacionados à frequência no uso do supermercado, ao transporte utilizado, à motivação de uso e apreço pela conversa foram cruzados com as informações relacionadas ao sexo. As informações de frequência de uso, transporte e conversas também foram correlacionadas com as faixas etárias. Desta forma, com as informações da estatística descritiva, delinearam-se alguns perfis de comportamento do idoso no supermercado.

\section{Resultados}

Foram aplicados questionários e coletadas informações com 150 idosos no bairro Areias do município de São José na grande Florianópolis, sendo 106 indivíduos entrevistados no supermercado e 44 indivíduos fora dele. Do total destes indivíduos, 67 eram homens (45\%) e 83 mulheres (55\%), como mostra o Gráfico 1.

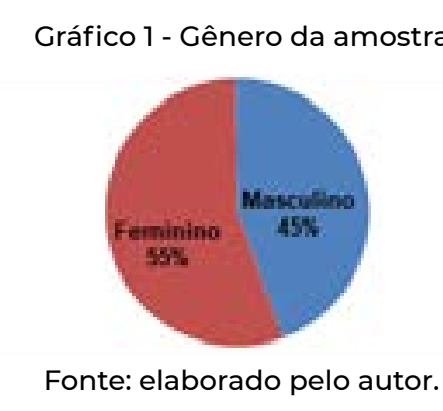

A média de idade dos entrevistados (Gráfico 2) ficou em 66,93 anos, sendo que os homens apresentaram a média de 65,93 anos e as mulheres 67,75 anos. A média de idade dos idosos brasileiros de 60 a 99 anos, segundo dados do IBGE (2015) em 2010 era de 68,37 anos, 68,88 anos para os homens e 70,35 anos para as mulheres.

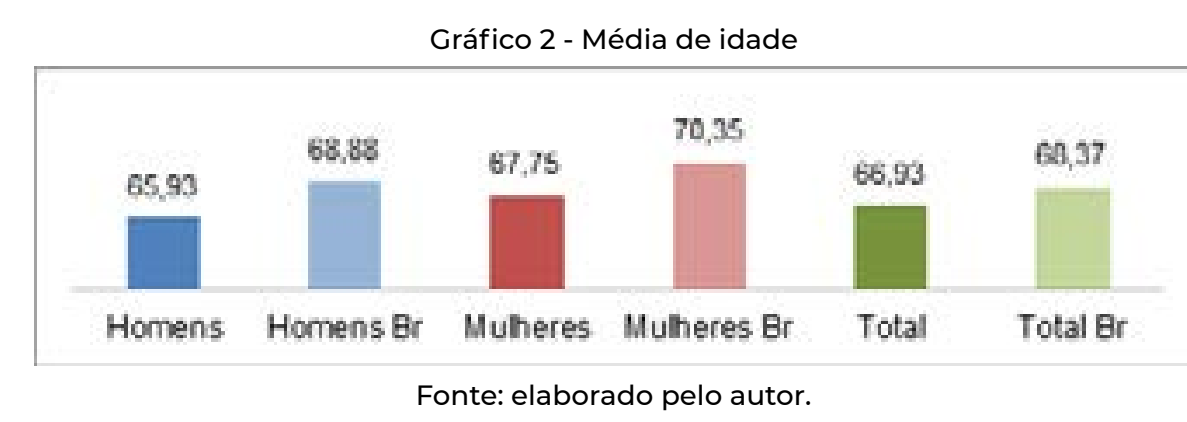

A diferença de média de idade entre a amostra coletada nesta pesquisa e a média de idade dos idosos brasileiros ficou acima de 2,5 anos, tanto para homens quanto para as mulheres, sendo que as médias brasileiras foram em todas superiores à amostra da 
pesquisa. A menor diferença ficou por conta da média de idade total dos idosos, sendo que a média de idade dos idosos brasileiros ficou apenas 1,44 anos maior que a média de idade da coleta (66,93 anos). Em 2000, segundo IBGE, 62,4\% (8,9 milhões) dos idosos eram responsáveis pelos domicílios e tinham, em média, 69 anos de idade, 2,07 anos a mais que a média de idade dos idosos desta amostra.

Para a comparação da amostra com a população idosa de Florianópolis, adotaramse as faixas de idade usadas pelo IBGE, conforme disposto no Gráfico 3 abaixo:

Gráfico 3 - Percentual por faixa etária por sexo (amostra X Florianópolis)

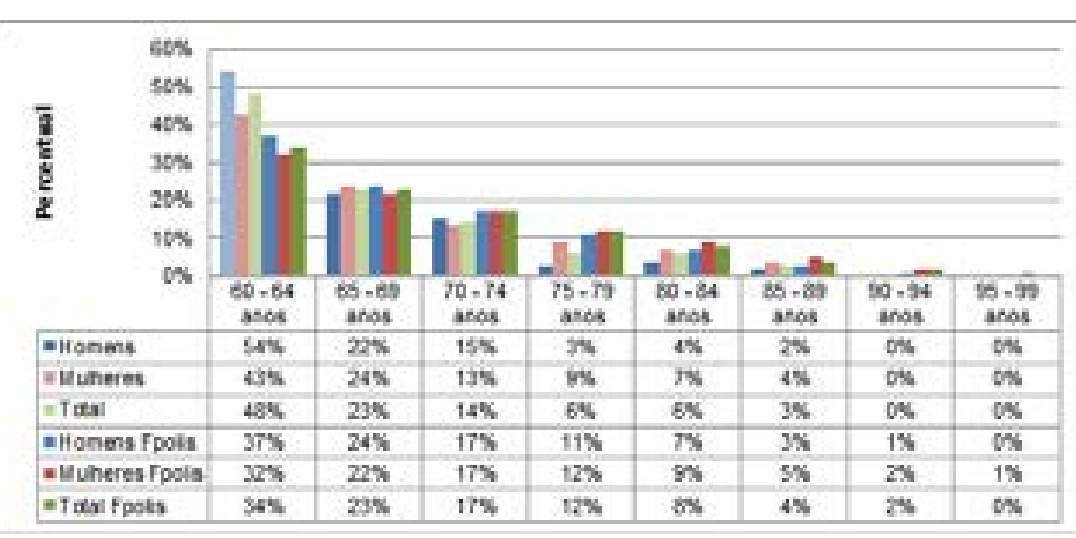

Fonte: elaborado pelo auto

Em comparação, as duas frequências apresentam naturalmente, a maio concentração do número de idosos por faixa na mais jovem (60 a 64 anos), porém a faixa mais jovem da amostra representa praticamente metade do número de indivíduos da pesquisa (54\% para homens, $43 \%$ para mulheres e $48 \%$ do total) contra um percentual médio menor da população de Florianópolis para a mesma faixa (37\% para homens, 32\% para mulheres e $34 \%$ no total). Este fato poderia ser explicado pela maior capacidade e facilidade motora dos idosos com idade entre 60 e 64 anos para a realização das tarefas relacionadas ao serviço de supermercado, assim frequentando mais esse tipo de estabelecimento. Com o avanço das faixas etarias, diminui a capacidade motora e cognitiva para o desempenho dessas atividades e consequentemente diminui a incidência de indivíduos em faixas etárias mais avançadas. De modo geral, as faixas superiores a 65 anos apresentam tendência ao equilíbrio, tanto na amostra, quanto na população de Florianópolis.

Já se tratando da faixa etária utilizada pela OMS, a faixa mais jovem (60 a 74 anos) também foi a que apresentou o maior percentual da amostra, com $91 \%$ dos homens, $81 \%$ das mulheres, totalizando $85 \%$ da amostra. Se for considerado que o avanço da idade causa a perda de habilidades físicas e cognitivas, este pode ser um fator de influência no grande percentual de indivíduos encontrados entre 60 e 74 anos de idade. Outro fator que poderia influenciar o resultado é a expectativa de vida (IBGE, 2017) dos idosos catarinenses (78,74 anos). A faixa "anciã" (75 a 89 anos) apresentou um percentua maior entre as mulheres da coleta (19\%) sendo que a expectativa de vida (IBGE, 2015) das mulheres catarinenses é de 82,1 anos de idade.

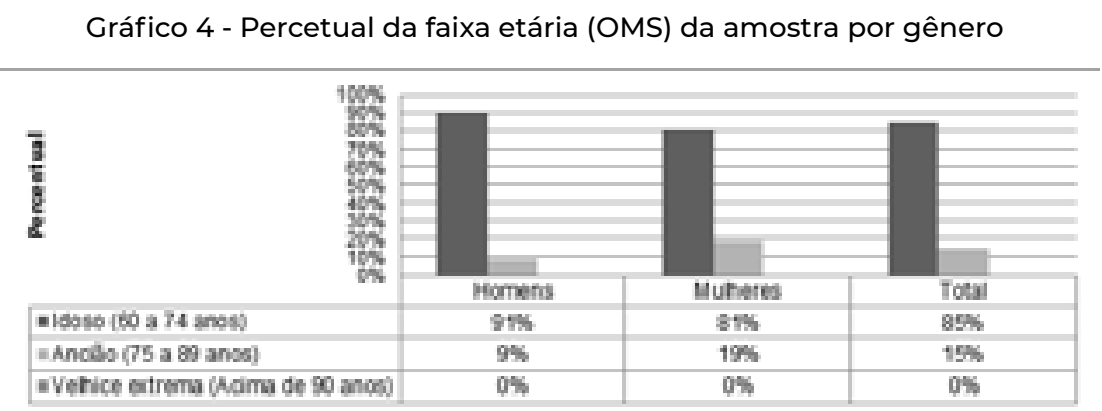

Fonte: elaborado pelo autor.

\subsection{Perfil do público idoso entrevistado}

Por meio do questionário aplicado foi possível fazer o levantamento de características do público idoso, relacionadas à frequência de utilização supermercados, meio de transporte utilizado, motivação para a utilização de um supermercado, e o gosto pela conversa nestes ambientes, e a partir dessas informações, correlacioná-las com informações que dizem respeito ao sexo e faixa etária, desta maneira delineando perfil do público pesquisado.

\section{Frequência de utilização de supermercados}

Em um panorama geral, a maior incidência de vezes que os usuários frequentam o supermercado é a de uma vez por semana, totalizando $37 \%$. Porém quando a questão é analisada por sexo, as frequências são outras. Enquanto $42 \%$ das mulheres frequentam o supermercado uma vez por mês, os homens mostraram-se mais frequentes no estabelecimento durante a semana, sendo $30 \%$ uma vez por semana e $28 \%$ afirmou usufruir diariamente o supermercado (Gráfico 5).

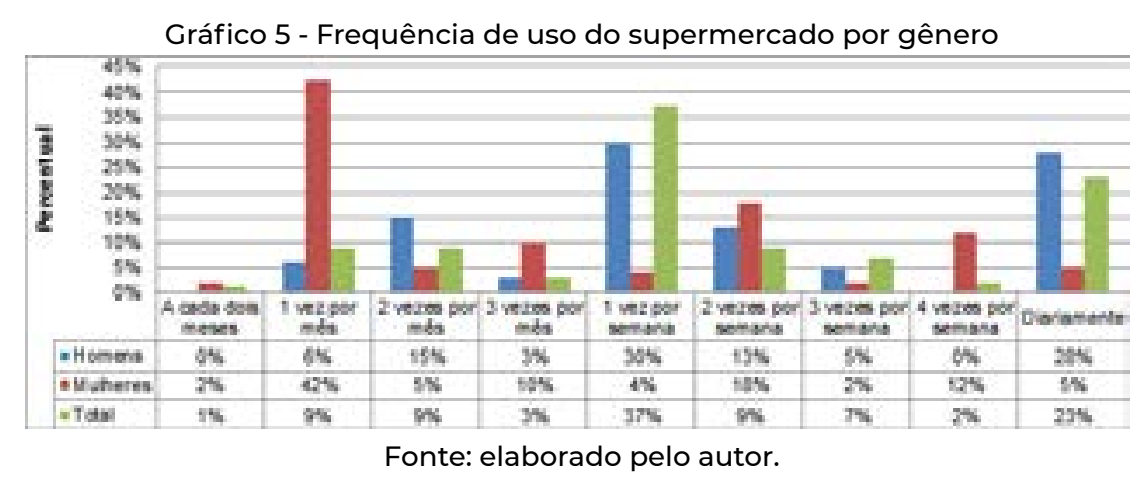

\section{Meio de transporte utilizado}

Foi questionado qual o meio de transporte mais utilizado para ir ao supermercado: a pé, bicicleta, carro próprio, ônibus, táxi, moto e outros (carona, por exemplo). Alguns sujeitos responderam mais de um meio de transporte usado, por isso na análise aparecem também opções com combinações de mais de um meio de transporte. Conforme mostra o Gráfico 6, mais da metade dos entrevistados afirmaram utilizar o carro como meio de transporte para se locomover (69\% dos homens, $57 \%$ das mulheres e $62 \%$ no total). 


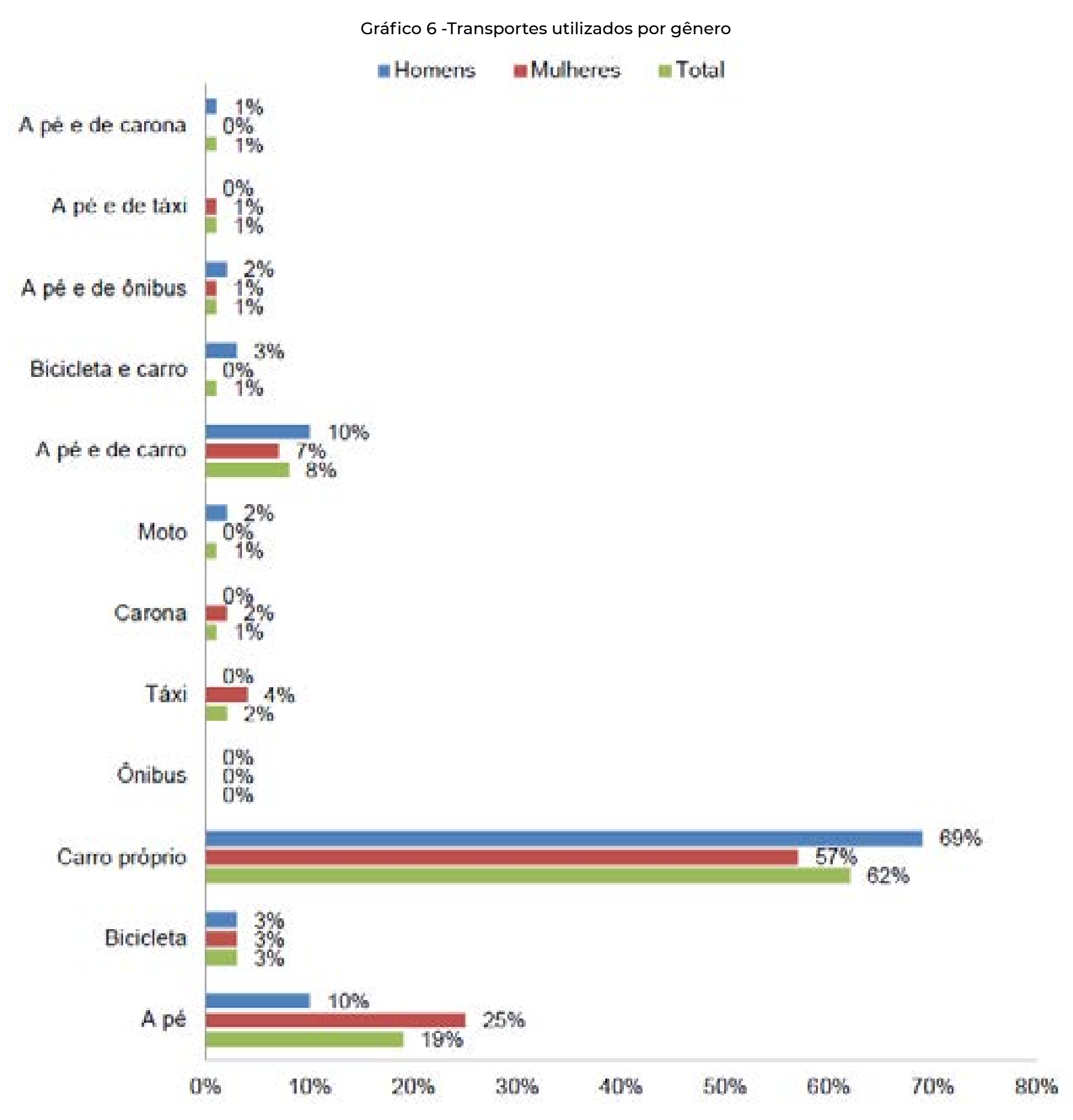

Fonte: elaborado pelo autor.

Independente da necessidade de transportar volumes quando se vai ao supermercado, pode-se comparar este gráfico com o percentual dos transportes mais utilizados em Florianópolis (gráfico 7), segundo Instituto MAPA (2011). Nele, "carro" e "à pé" estão entre os três transportes mais utilizados ( $41 \%$ e $11 \%$, respectivamente), sendo que na amostra dos idosos entrevistados no supermercado (gráfico 6) "carro" e "à pé" apresentaram os maiores percentuais (62\% e $19 \%$ respectivamente).
Já em um comparativo do transporte mais utilizado (carro) e o meio de locomoção que exige mais da capacidade física do idoso (andar a pé) com relação às faixas de idade, mostram que ambos têm uma incidência equivalente à de mais de dois terços dos indivíduos na faixa mais jovem. Conforme Gráfico $8,75 \%$ do total a pé, sendo que $86 \%$ dos homens e $71 \%$ das mulheres possuem idades entre 60 e 74 anos. Dos usuários de carro como transporte, a mesma faixa prevaleceu, com o percentual de $90 \%$ no total, sendo $88 \%$ entre os homens e $87 \%$ entre as mulheres.

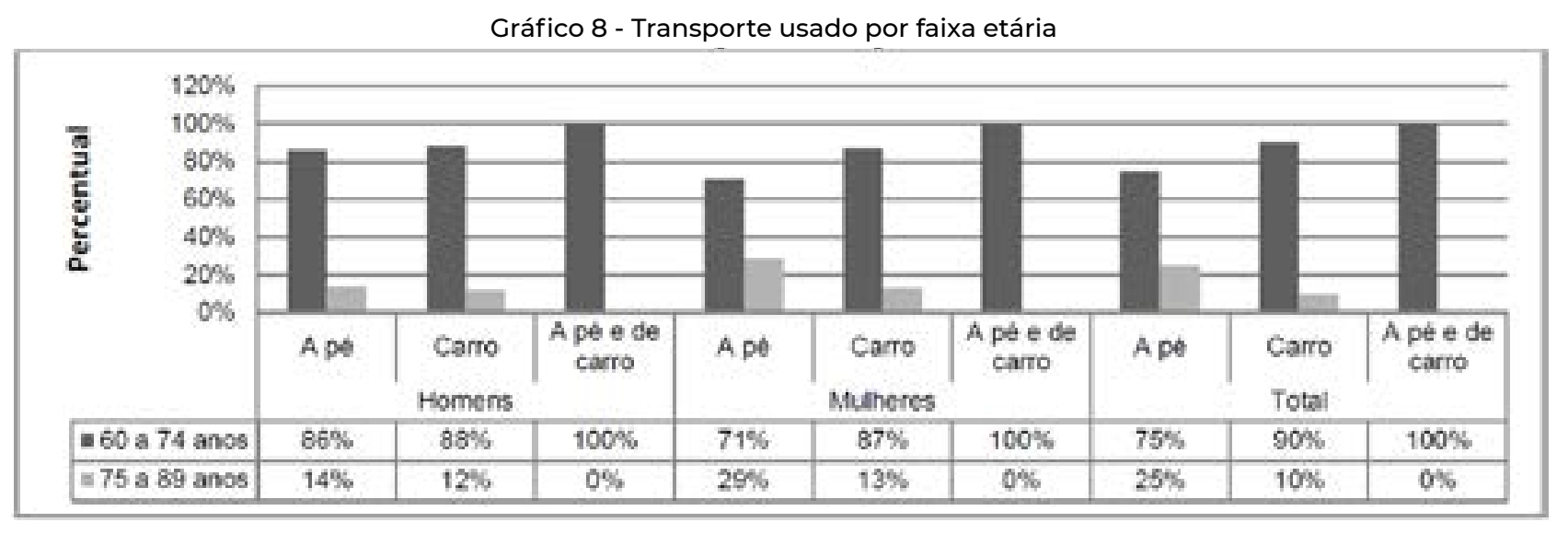

Fonte: elaborado pelo autor

\section{Motivação para a utilização de supermercados}

A maioria dos entrevistados (Gráfico 9) afirmou utilizar o supermercado por necessidade ( $74 \%$ no total, sendo $66 \%$ das mulheres e $84 \%$ para os homens). Outras motivações que surgiram na pesquisa apresentaram valores relativamente baixos (entre 1\% e 3\%), com exceção para a afirmação "fazer compras" (que está ligada ao comprar por lazer) que teve a incidência de $10 \%$ no total (16\% entre as mulheres e $4 \%$ para os homens). 
Gráfico 9 - Motivação na utilização do serviço por gênero

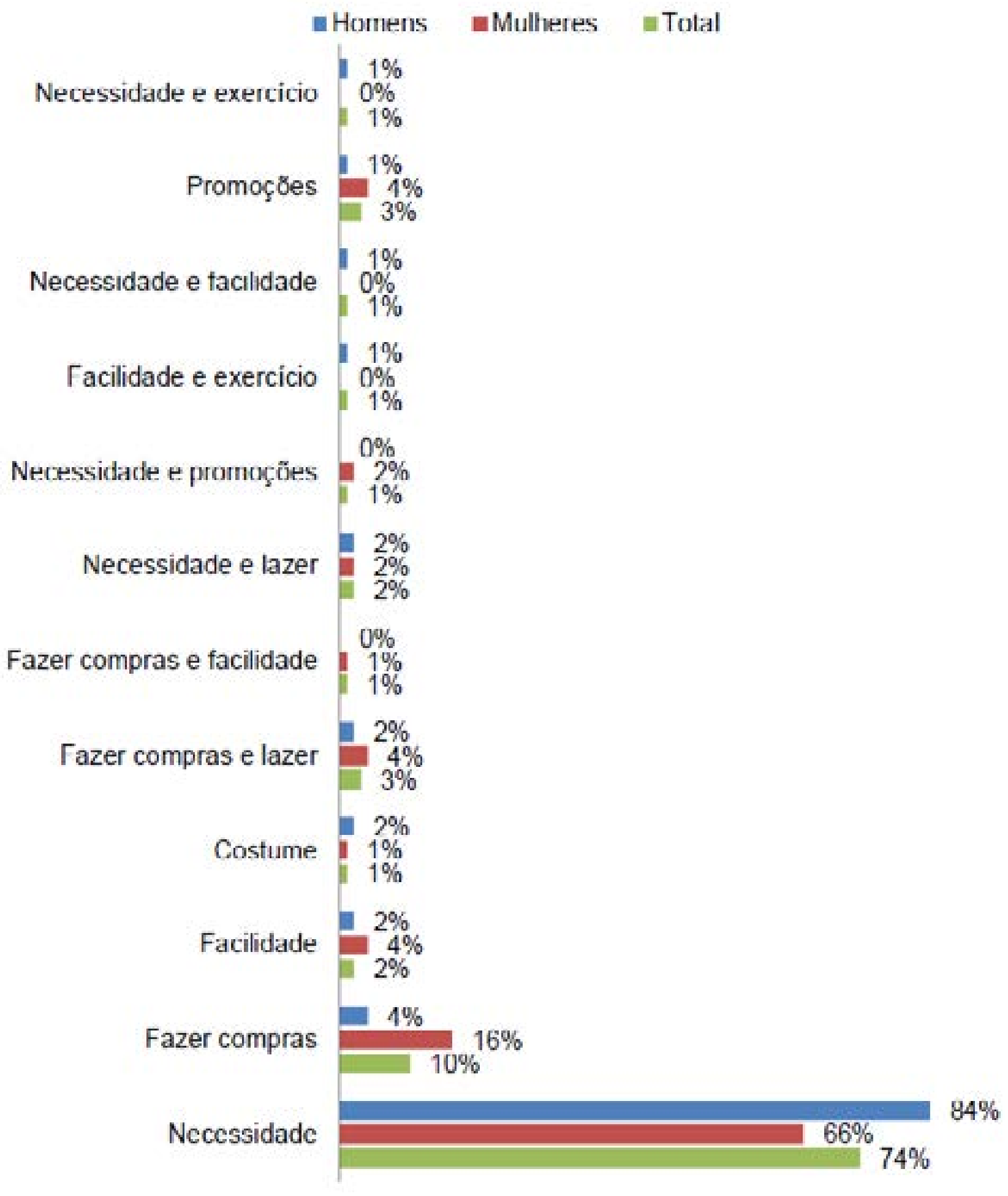

Fonte: elaborado pelo autor.

\section{Apreciação pela conversa em ambientes de supermercados}

Como mostra o Gráfico 10, mais da metade dos entrevistados afirmaram ter apreço pela conversa ( $57 \%$ no total), demonstrando estimo por certo grau de socialização.
Contudo, as mulheres se mostraram mais abertas para conversas dentro desse tipo de estabelecimento (63\% afirmaram gostar de conversar), enquanto, entre os homens, os percentuais estiveram equilibrados (49\% gostam de conversar e $51 \%$ não gostam).

Gráfico 10 - Apreço pela conversa por gênero

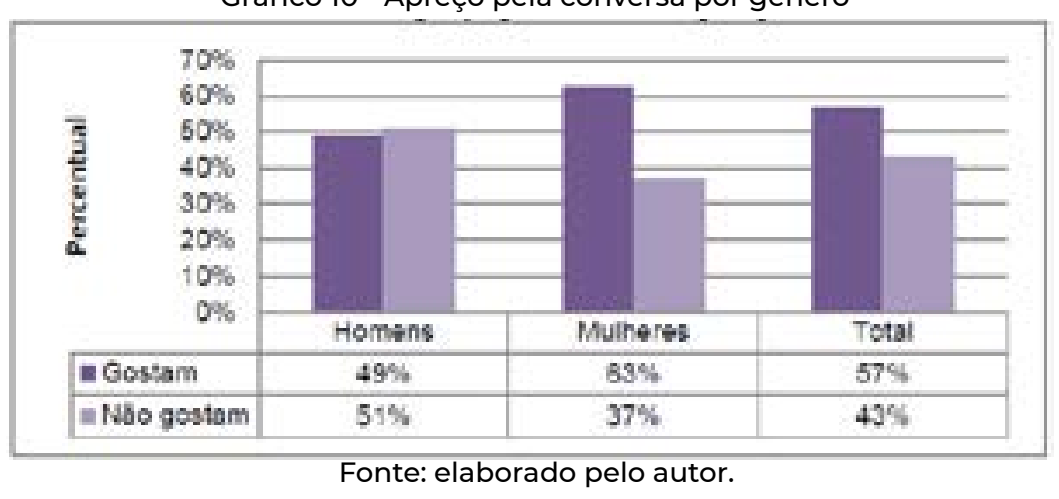

Dentre os usuários que afirmaram gostar de conversar, a maioria situou-se na faixa de 60 a 74 anos, apresentando o percentual de $82 \%$ no total, $85 \%$ entre os homens e $81 \%$ entre as mulheres. Na faixa de 75 a 89 anos o percentual dos que gostavam ficou em torno de $18 \%$ ( $15 \%$ entre os homens e 19\% entre as mulheres). Já os entrevistados que afirmaram não gostar de conversar, o percentual total na faixa mais jovem foi de $89 \%, 97 \%$ entre os homens e $89 \%$ entre as mulheres. E o percentual apresentado na faixa de 75 a 89 anos dos que não gostam de conversa, os homens apresentaram um percentual de apenas 3\%, as mulheres $19 \%$ e o percentual total foi de $11 \%$.

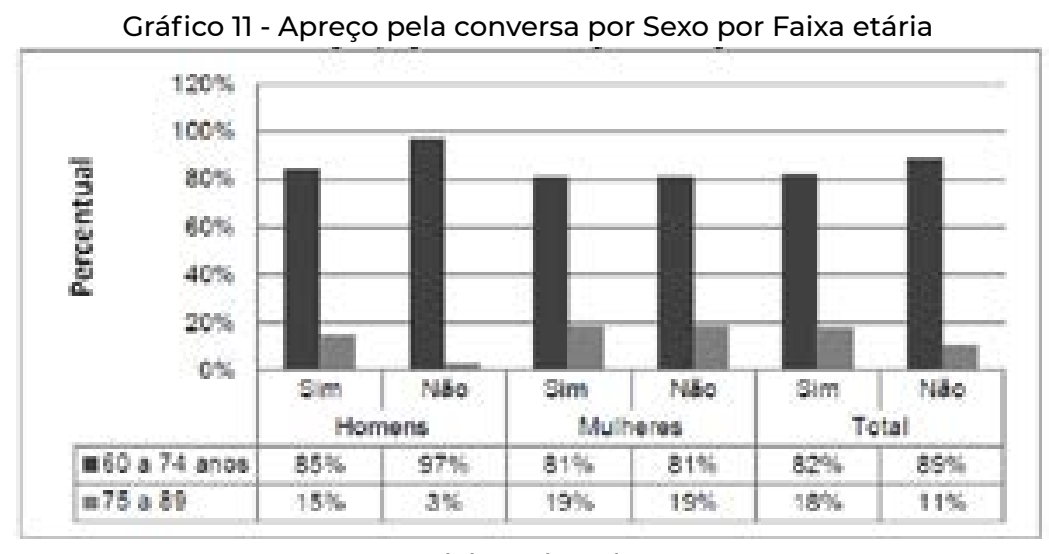

Fonte: elaborado pelo autor.

\section{Discussão}

As maiores diferenças encontradas nas distribuições de frequência dos dados analisados na estatística descritiva se deram por conta das diferenças nas faixas etárias e sexo dos indivíduos. Com o avanço da idade, as habilidades psicomotoras, perceptivas e cognitivas decaem (HIGGINS; GLASGOW, 2012), desta forma fazendo com que idosos com idades mais avançadas apresentem maiores dificuldades para a realização de atividades corriqueiras, como a utilização do serviço de supermercado. Para que 
os produtos, neste caso serviços, sejam funcionais, seguros, eficientes e atrativos, é necessário serem consideradas as mudanças advindas da idade, sejam motoras ou cognitivas (HAIGH, 1993).

Diferenças relacionadas ao sexo (gênero), como o apreço pela conversa, podem ser explicadas devido a aspectos comportamentais e culturais, resultando em diferentes experiências de compras e respostas do cliente (BURT; GABBOTT, 1995). Contudo outros fatores devem ser observados e que refletem nos resultados, como é o fato das mulheres apresentarem maior expectativa de vida (IBGE, 2015), sendo a média das brasileiras de 78,6 anos e 81,4 anos a média das catarinenses, contra 71,3 anos a média dos homens brasileiros e 74,7 anos a média dos homens catarinenses.

O transporte mais utilizado foi o carro (62\%), sendo que, entre a população de Florianópolis em geral, em 2011, este meio de transporte também apresentou o maio percentual de $41 \%$, segundo o Instituto MAPA (2011). Um fator que pode influenciar esses resultados é a política de facilitação a financiamento para a aquisição de automóveis sob o pretexto de ser uma ação para enfrentar crises econômicas e desemprego os incentivos do governo ao uso do transporte individual (GONTIJO; GUIDI, 2013).

Outro fator a ser considerado são as dificuldades motoras enfrentadas pelos idosos, o que incentivaria o uso do carro. Por outro lado, tem-se que as habilidades psicomotoras, perceptivas e cognitivas decaem (HIGGINS; GLASGOW, 2012), o que dificultaria o uso do automóvel particular, e restringiria ao uso do transporte público ou o transporte a pé. Contudo, não foi encontrado nenhum indivíduo da amostra que utilizasse o ônibus como meio de transporte para o supermercado, o que pode indicar que as limitações físicas e cognitivas que poderiam dificultar a condução de veículos e são mais impeditivas ao porte de volumes (sacolas) no uso de transportes públicos. Segundo o Instituto MAPA (2011), em Florianópolis, em 2011, 63\% das pessoas nunca ou raramente utilizaram o transporte coletivo. Para os idosos, um agravante estaria na dificuldade em realizar algumas tarefas cotidianas, como sentar, levantar e subir e descer escadas (ANDREAOTTI; OKUMA, 1999), portanto andar de ônibus.

Com base na fundamentação teórica e observações em campo, notou-se o apreço dos usuários idosos de supermercado pelos aspectos sociais proporcionados. As pessoas, além de comprar, desejam manter relações sociais com os outros através das compras (MILLER, 2002; DOUGLAS; ISHERWOOD, 2006). Contudo, a amostra quando questionada sobre a motivação de uso do supermercado e o apreço pela conversa, não se mostrou muito preocupada com a socialização. A diferença entre os homens pelo gosto da conversa foi de apenas $2 \%$, sendo que a maioria afirmou não gostar de conversar (51\%). No total a diferença de percentual foi de $14 \%$ a mais para o gosto pela conversa.

A maior motivação para a utilização do serviço foi a "necessidade" (74\%), sendo que motivos relacionados à socialização e lazer apresentaram percentuais relativamente baixos. Assim, podemos afirmar ao menos, com base nas respostas dos usuários idosos deste supermercado, que estes são na maioria compradores funcionais, em contraponto à pesquisa de Balazs (1994) que apontou que 70\% de seus entrevistados poderiam ser categorizados como compradores recreativos.

\section{Conclusão}

A identificação e delimitação das formas de consumo, necessidades, vontades e limitações do idoso em um supermercado mostra-se um excelente aliado no desenvolvimento da melhor experiência de consumo do serviço de supermercados por esse público. Contudo o estudo da experiência do usuário ainda é algo recente, com definições diversas, o que dificulta a delimitação dos fatores que compreendem a experiência de consumo. Em contraponto, têm-se também as diferenças culturais, sociais e de perfil que influem e resultam em diferentes experiências de compras e, finalmente, diferentes respostas do consumidor dentro do mercado para idosos (BURT; GABBOTT, 1995). Por isso é preciso entender a realidade do consumidor idoso brasileiro em supermercados para poder perceber suas necessidades e vontades pontuais com intuito de proporcionar a melhor experiência para esse público.

As questões que envolveram o uso do supermercado e as referentes ao cadastro mostraram resultados interessantes e mais ricos do que os esperados. Quando relacionadas entre si e com dados estatísticos da população catarinense e brasileira puderam delinear melhor o perfil deste usuário idoso e reforçar algumas fundamentações que dizem respeito ao envelhecimento, limitações, vontade e necessidades da população sênior.

Desta forma, com base em alguns aspectos observados e levantados na pesquisa aqui demonstrada com relação a comportamentos e perfis notados, construiu-se a Tabela 2 a seguir apontando alguns requisitos de projeto e ponderando se estes são de natureza cognitiva, física ou social. 
Tabela 2- Faixa etária OMS

\begin{tabular}{|l|l|}
\hline COMPORTAMENTO / REQUISITOS & NATUREZA \\
\hline Idoso apresentam dificuldade com TI & Cognitiva \\
\hline Devem ser considerados o translado de ida e vinda do idoso & Física \\
\hline Vagas de estacionamento amplas & Física \\
\hline Sinalização clara e de fácil compreensão dotadas de ilustrações & Cognitiva \\
\hline $\begin{array}{l}\text { Prateleiras com alturas mais baixas para que o usuário possa ver o res- } \\
\text { tante da loja }\end{array}$ & Física e Cognitiva \\
\hline Boa visão geral da loja e navegação intuitiva & Física e Cognitiva \\
\hline Espaços para repouso & Física e Social \\
\hline Agradável atmosfera de compra & $\begin{array}{l}\text { Física, Cognitiva e } \\
\text { Social }\end{array}$ \\
\hline Preços e rótulos visíveis e de fácil leitura & Cognitiva \\
\hline Chão com piso antiderrapante & Física \\
\hline Interação pessoal e amigável com o consumidor & Social \\
\hline Áreas com possibilidade para socializar com outras pessoas & Social \\
\hline Bom serviço & Social \\
\hline
\end{tabular}

Fonte: Elaborado pelos autores, com base na pesquisa realizada.

Por fim, designers e demais responsáveis pelo desenvolvimento de serviços devem se esforçar para contrabalancear e entender a experiência do usuário, bem como os elementos que a compõem, para concepção de serviços condizentes com as particularidades do público destinado, como por exemplo, a população idosa. Portanto, visualizou-se com este trabalho, que pesquisas envolvendo consumidores idosos, bem como a produção científica envolvendo a experiência de uso de serviços e design de serviços ainda são pequenas, e são ainda menores quando voltadas para a realidade brasileira. Portanto é perceptível a oportunidade de propostas para estudos futuros, realizando a abordagem da temática utilizando outras perspectivas de coletas de dados, o desenvolvimento de ferramentas que tangenciem os aspectos da experiência, e a criação de um estudo de caso envolvendo a aplicação dos aspectos da experiência no desenvolvimento de um serviço.

\section{Referências}

ANDREAOTTI, R. A: OKUMA, S. S.Validação de uma Bateria de testes de atividades da vida diária para Idosos fisicamente independentes. Ver. Paul Educ. Fis.13:46-66, 1999. BALAZS, A. The eldermall: exploring new ways to position the aging retail shopping center for aging consumers. Journal of Shopping Center Research, 1, 39-64, 1994.

BALLSTAEDT, A. L. M. P. Comportamento e estilo de vida da população idosa e seu poder de consumo. In: Encuentro Latinoamericano de Diseño, 2. Anales. Buenos Aires, 2007. Disponível em: <http://fido.palermo.edu/servicios_dyc/encue

tro2007/02_auspicios_publicaciones/actas_diseno/articulos_pdf/A004.pdf $>$. Acesso em 17 set. 2013.

BRIGHAM, B. Trends in retail design. Informe design, 3(8). 2005.

BURT, S.; GABBOTT, M. The elderly consumer and non-food purchase behaviour. European Journal of Marketing, 29(2), 43-57. 1995.

CICIRELLI, V. G. Family support in relation to health problems of the elderly. In T.H. Brubaker(ed.), Family relationships in later life. 2nd ed.. Newbury Park, CA: Sage, p.212228. 1991.

COCKERHAM, W. This aging society. New Jersey: Prentice Hall, 1991.

DEBERT, G. G. A Reinvenção da Velhice: socialização e processos de reprivatização do envelhecimento. São Paulo: Fapesp, 1999. 272p.

DEMILIS, M. P. Fatores Humanos no Design de serviços: Valoração de aspectos da experiência de consumo pelo público idoso em supermercados. Florianópolis, 2015. 135 p. Dissertação (Mestrado em Design) - Programa de Pós Graduação em Design PPGDesign, Universidade do Estado de Santa Catarina, 2015.

DEMILIS, M. P. REIS, A. A. SANTOS, F. A. N. V. Influência da avaliação comportamental de consumo do idoso na ergonomia organizacional de supermercados. Human Factors in Design, v. 6, p. 15-27, 2017.

DOUGLAS, M. ISHERWOOD, B. O mundo dos bens: para uma antropologia do consumo. Ed. UFRJ: Rio de Janeiro, 2006

GREER HUSS PACE, M. Preferences for universal design features in apparel retail stores by older female apparel customers. Columbus, OH: Ohio State University. 2006.

HAIGH, R. The ageing process: a challenge for design. Applied ergonomics, v. 24, n.1, p. 9-14, fev. 1993. 
HIGGINS, P. G.; GLASGOW, A. Development of guidelines for designing appliances for older persons. A Journal of Prevention, Assessment \& Rehabilitation, v. 41, n.1, p. 333-339, 2012.

INSTITUTO BRASILEIRO DE GEOGRAFIA E ESTATíSTICA (IBGE). Projeção da população do Brasil e das Unidades da Federação. Disponível em: http://www.ibge.gov.br/apps/ populacao/projecao/ Acesso em: dez. 2017

HOUSE, J.; LANDIS, K, e UMBERSON, D. Social relationships and health.Science, 241 p.540-544. 1998

KIM, Y. KANG, J. KIM, M. The relationships among family and social interaction, loneliness, mall shopping motivation, and mall spending of older consumers. Psychology \& Marketing, 22(12), 995-1015. 2005

MAPA - Instituto MAPA: Pesquisas e Informações Estratégicas. 2011. Disponível em: http://www.mapa.com.br/\#. Acesso em abril de 2015

MILLER, D. Teoria das compras. São Paulo: Nobel, 2002.

PETERMANS, A.M.S. VAN CLEEMPOEL, K. Designing a retail store environment for the mature market: a European perspective. Journal of Interior Design, Vol.35 No.2 pp2136. 2010

PINE, J., \& GILMORE, J. H. The experience economy: Work is theatre and every business a stage. Boston: Harvard Business School Press. 1999.

PINE, J. GILMORE, J. AUTHENTICITEIT. Wat consumenten echt willen. Den Haag: Academic Service. 2008

RAMOS, M. P. Apoio social e saúde entre idosos. Sociologias, Porto Alegre, ano $4, \mathrm{n}^{\circ} 7$, p.156-175, jan/jun 2002

SANTOS, F. H. DOS; ANDRADE, V. M.; BUENO, O. F. A. Envelhecimento: um processo multifatorial. Psicologia em Estudo, Maringá, v. 14, n. 1, p. 3-10, jan./mar. 2009.

SCHMIDT, R.; SEGAL, R; CARTWRIGHT, C. Two-stop shopping or polarization? Whither UK grocery retailing? International Journal of Retail and Distribution Management, 22(1), 12-19. 1994.

SHERMAN, E.; SCHIFFMAN, L.; MATHUR, A. The influence of gender on the new-age elderly's consumption orientation. Psychology\& Marketing, 18(10), 1073-1089. 2001

SILVERSTEIN, M.; BENGTSON, V. L. Does intergenerational social support infl uence the psychological well-being of older parents? The contingencies of declining health and widowhood. Social Science and Medicine, 38(7), 943-957. 1994.
World Health Organization (OMS ou WHO). Ageing and Health Programme Division of Health Promotion, Education and Communication. The Hildelberg guidelines for promoting physical activity among older persons: guidelines series for healthy ageing - I. Heidelberg, Germany:August, 1996. Disponível em: www.who.org. Acessado em: 06 dez. 2014. 